Vasilyeva, G. V., E. A. Zhuk and A. G. Popov (2010): Flowering phenology of the Siberian stone pine (Pinus sibirica Du Tour), Japanese stone pine (Pinus pumila (Pall.) Regel.) and their hybrids. Vestnik Tomskogo gosudarstvennogo universiteta. Biologia 1(9): 61-67. (In Russian)

Vasilyeva, G.V., S.N. Goroshkevich and A. G. Popov (2006): Natural hybridization between Siberian stone pine and Siberian dwarf pine in the Northern Pribaikalye (delta of the Upper Angara River): occurrence of hybrids and their cone bearing, pp. 195-199. In: Forest ecosystems of Northern-Eastern Asia and their dynam- ics. Proceeding of international conference, 22-26 august 2006. Dalnauka, Vladivostok. (In Russian)

Utkin, A. I., A. A. Pryazhnikov and D. V. Karelin (2001): Ecology of Siberian dwarf pine from a position of carbon cycle. Lesovedenie 3: 52-62. (In Russian)

WACHOWIAK, W., A. LeWANDOSWKI and W. PRUs-Glowacki (2005): Reciprocal controlled crosses between Pinus sylvestris and $P$. mugo verified by a species-specific cpDNA marker. J. Appl. Genet. 46: 41-43.

WIENS, D. (1984): Ovule survivorship, brood size, life history, breeding systems, and reproductive success in plants. Oecologia 64: 47-53.

\title{
Computer Simulation for the Evaluation of Recombination Strategies in Intrapopulation Recurrent Selection in Eucalyptus
}

\author{
By G. B. Abreu ${ }^{1), *}$, D. F. Ferreira ${ }^{2)}$, M. A. P. Ramalho ${ }^{2)}$, F. H. R. B. Toledo ${ }^{3)}$ and J. S. De Sousa Bueno Filho ${ }^{2)}$
}

(Received $14^{\text {th }}$ August 2012)

\begin{abstract}
Intrapopulation recurrent selection (IRS) has proven to be a promising breeding method in eucalyptus, mainly through being easier to carry out when compared to reciprocal recurrent selection (RRS). However, the recombination strategies in IRS that have not yet been compared. Thus, the purpose of this study was to verify the efficiency of different recombination methods in IRS. To do so, computer simulation was used considering different heritabilities $(0.1,0.5,1.0)$, different initial allelic frequencies $(0.2,0.8)$ and allelic interactions without dominance and with complete dominance. The initial population consisted of 1000 individuals, which were selected at random for the beginning of cycle zero. These individuals were interbred two by two. Three selection strategies were carried out and, consequently, three recombination methods: recombine the best individuals selected within the best progenies; the best individuals phenotypically selected regardless of their genealogy; or selection in the mean value of the best progenies selected. It was observed that recombination of the best individuals regardless of their genealogy and of the best individuals within the best progenies provided for gains superior to recombination having only the mean of the progenies as reference. The average degree of domi-

\footnotetext{
1) Embrapa Cocais, Av. Santos Dumont Anil, 18, 65046-660, São Luis MA.

2) Universidade Federal de Lavras, Caixa Postal 3037, 37200000, Lavras MG

3) ESALQ Av. Pádua Dias, 11, 13418-900, Piracicaba SP.

*) Corresponding author: Guilherme Barbosa Abreu. Embrapa Cocais, Av. São Luís Rei de França Conjunto Eldorado, 4, 65065-470 São Luís MA - Brazil. E-Mail: guilherme.abreu@ embrapa.br
}

nance and the heritability of the trait should be considered at the time of choosing the method of selection followed by recombination.

Key words: Forest breeding, Quantitative Genetics, Monte Carlo, Breeding Strategies, Genetic Gain.

\section{Introduction}

Eucalyptus cultivation plays an important role in Brazilian agribusiness through the use of your production of charcoal, cellulose, posts, poles, lamination, lumber and other items (RESENDE et al., 2011). This success is due to genetic breeding, which, together with the areas of nutrition, management and forest conservation, have led to transformation of the country into the world's largest producer of eucalyptus in a short period of time (VILLARI, 2010).

Until recently, the strategy of obtaining clones was predominantly by means of selection of individuals on commercial plantations. Initially this was highly successful; however, "resampling" in the same population does not allow future gains (GONÇALVES et al., 2001). For that reason, the need was envisaged for promoting populational breeding before the selection of individuals for cloning.

Proposals for use of Reciprocal Recurrent Selection (RRS) have been presented (RESENDE et al., 2011). However, RSS is time consuming, laborious and conditioned on the existence of expressive dominance in the trait under selection. Moreover, RRS is static because two populations are selected with a view towards the improvement of heterosis between them. If the involvement of another species or other individuals is required, 
their inclusion in the process is problematic. On the other hand, and since heterosis is not very pronounced between eucalyptus species (Bouvet et al., 2009), Intrapopulation Recurrent Selection (IRS) is an excellent option in breeding of this specie. Through use of IRS, the base population may be synthetic, i.e., originating from crossing of duly evaluated clones/individuals belonging to one or more species. That way, the synthetic population may join conditions for selection of some traits at the same time.

In conducting IRS in eucalyptus, the literature basically proposes two alternatives for recombination. One of them involves interbreeding of the best individuals within the best progenies. This procedure, although easily applied, has some drawbacks of a practical order due to many clearings in the field, hindering recombination between the selected individuals. In addition, if the selection is early, there is no way to prove its effectiveness since most of the trees are cut down. Another option would be the use of remnant seeds. In this case, after early selection, plants of the best progenies derived from remnant seeds would be grown in an isolated group. That way, at the time of flowering, the experiment would already be more years along and the performance of the selected progenies could be confirmed (PEREIRA et al., 1997).

With the ease of artificial hybridizations in eucalyptus (Assis et al., 1993; Assis et al., 2005), the use of full sibs is viable, in which recombination is directed and therefore more efficient than free interbreeding. In addition, the best individuals of the best progenies may be cloned for more intensive evaluation in clone tests, as well as allowing various copies of the same tree to be obtained for recombination. The clonal test may be evaluated early and this allows one to recombine only the progenies/individuals whose clones are really the best. In this situation, recombination is much more efficient because, in addition to the crosses of the best progenies/clones being directed, the decision in respect to the individual to be cloned is performed with greater accuracy.

The question that arises is in regard to the best option: recombine the individual itself that was cloned, or interbreed the progenies that generated the best individuals. In recombination, the question also arises if the performance of the progeny should be considered or if only the information of the individual that was selected should be used. An answer to these questions is practically impossible under field conditions due to the time and space necessary to achieve a conclusive answer. The alternative is the use of computer simulation because it allows the generation of various population types and, above all, it makes an evaluation of the medium and long term response viable (SHELBOURNE et al., 2007).

Therefore, the objective of this study was to verify, by means of computational simulation, the best recombination strategy in intrapopulation recurrent selection of eucalyptus, using full sibs progenies.

\section{Material and Methods}

Computer simulation was used to determine the best method of recombination in intrapopulation recurrent selection based on a population. Different allelic frequencies, heritabilities and types of allelic interactions were considered. Each configuration proposed in advance was repeated 100 times. The scenarios are detailed below.

Populations of 1000 individuals $(n)$ were simulated considering traits with polygenic control of 100 loci $(g)$ of equal and independent effects. The genetic model proposed did not consider epistasis. The frequencies of the favorable allele $(p)$, in the population of cycle 0 , were 0.2 and 0.8 in the mean of the $\mathrm{g}$ genes considered. The $B$ allele was considered as favorable and the $b$ as unfavorable. The additive value $(a)$ was considered as 1 . Thus, when the allelic interaction of the complete dominance type was considered, the value of ' $d$ ' was also 1 (one) and without dominance ' $d$ ' was 0 (zero).

That said, the phenotypic value $\left(V_{F_{i}}\right)$ of the individual $i$ was obtained by $V_{F_{i}}=G_{i}+e$, where $G_{i}$ is the sum of the 100 genes considered and e is the error term. The genotypic variance was obtained as being the variance of the genotypic values of the individuals of the base population. The environmental deviation, or error term $(e)$, was

Table 1. - Configurations used in simulation considering different heritabilities $\left(\mathrm{h}^{2}\right)$, allelic frequencies and average degree of dominance.

\begin{tabular}{cccc}
\hline Configurations & $\mathrm{ADD}^{1}$ & $\mathrm{~h}^{2}$ & Allelic Freq \\
\hline 1 & 0 & 0.1 & 0.2 \\
2 & 0 & 0.1 & 0.8 \\
3 & 0 & 0.5 & 0.2 \\
4 & 0 & 0.5 & 0.8 \\
5 & 0 & 1.0 & 0.2 \\
6 & 0 & 1.0 & 0.8 \\
7 & 1 & 0.1 & 0.2 \\
8 & 1 & 0.1 & 0.8 \\
9 & 1 & 0.5 & 0.2 \\
10 & 1 & 0.5 & 0.8 \\
11 & 1 & 1.0 & 0.2 \\
12 & 1 & 1.0 & 0.8 \\
\hline
\end{tabular}

${ }^{1}$ Average degree of dominance: 0 (zero) = without dominance, 1 (one) = complete dominance. 
obtained as of a normal distribution with zero mean and standard deviation according to pre-established heritabilities $\left(h^{2}=0.10 ; 0.50\right.$; and 1.00).

The different configurations, that is, the variations in the average degree of dominance, heritability and allelic frequency of the initial population are presented in Table 1.

\section{Selection and recombination of the individuals of the cycle zero}

By means of demosntration, it was shown details of the simulation process. It was used only functions of the base package of the $\mathrm{R}$ software, basically the pseudorandom numbers generators, following statistics distributions (R Development CoRe Team, 2010).

In the simulation implementation of the initial population, given the allele frequency, it was used the beta and uniform distribution. $g$ values were generated from both distributions for each $\mathrm{n}$ individuals. If the uniform value is smaller than the square of beta value, the loci receive the recessive genotype (- $a$, or genotype $b b$ ), if the uniform value is among the square of beta value and 2 times beta value multiplied by one minus beta value, the loci receive the heterozigous value $(d$, or genotype $B b)$. The values of the uniform greater than these receive the genotype $B B$ (or $a$ value). The sum of the genotype values by each individual is the total genetic value $(G)$. The variance between the $G s$ was taken as genetic variance. Normal values with zero mean and standard deviations according to the heritabilitie simulate were generated and added to genotipic value resulting in fenotipic values. After all, for each one of $n$ individuals, in $g$ loci, it is ensured that the genotipic values, by loci, are independent and are in Hardy-Heinberg equilibrium. That process was implemented in $\mathrm{R}$ language as:

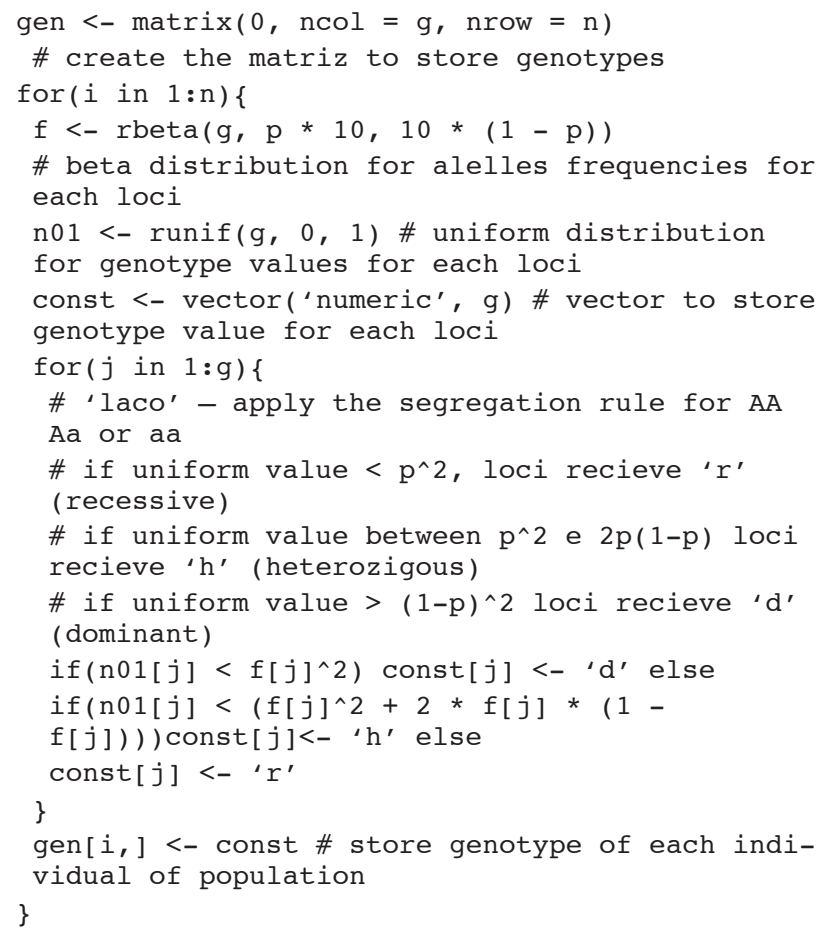

The selection of 20 individuals in the base population was performed at random and afterwards they were recombined two by two, generating 190 progenies. Each progeny consisted of 20 individuals. The values were stored, identifying their genealogy, in other words, which individuals (in the base population) were their parents.

To cross two individuals it was used the follow segregation rule: the loci that both parents were homozygous, dominant or recessive, the genotype value of the son was taken as homozygous, dominant or recessive, respectively. Loci that one parent was homozygous recessive and other homozygous dominant the son receive the heterozygote value. If both parents were heterozygote, the son loci values were a sample of the multinomial distribution with probabilities taken as: $a=0.25 ; d=0.5$; and $-a=0.25$. And for loci with one homozygous parent (recessive or dominant) and the other heterozygous parent, the distribution used was binomial with probability of success equal to 0.5 ( $a$, or $-a$ ), depending on the parents genotype. This implementation in $\mathrm{R}$ is:

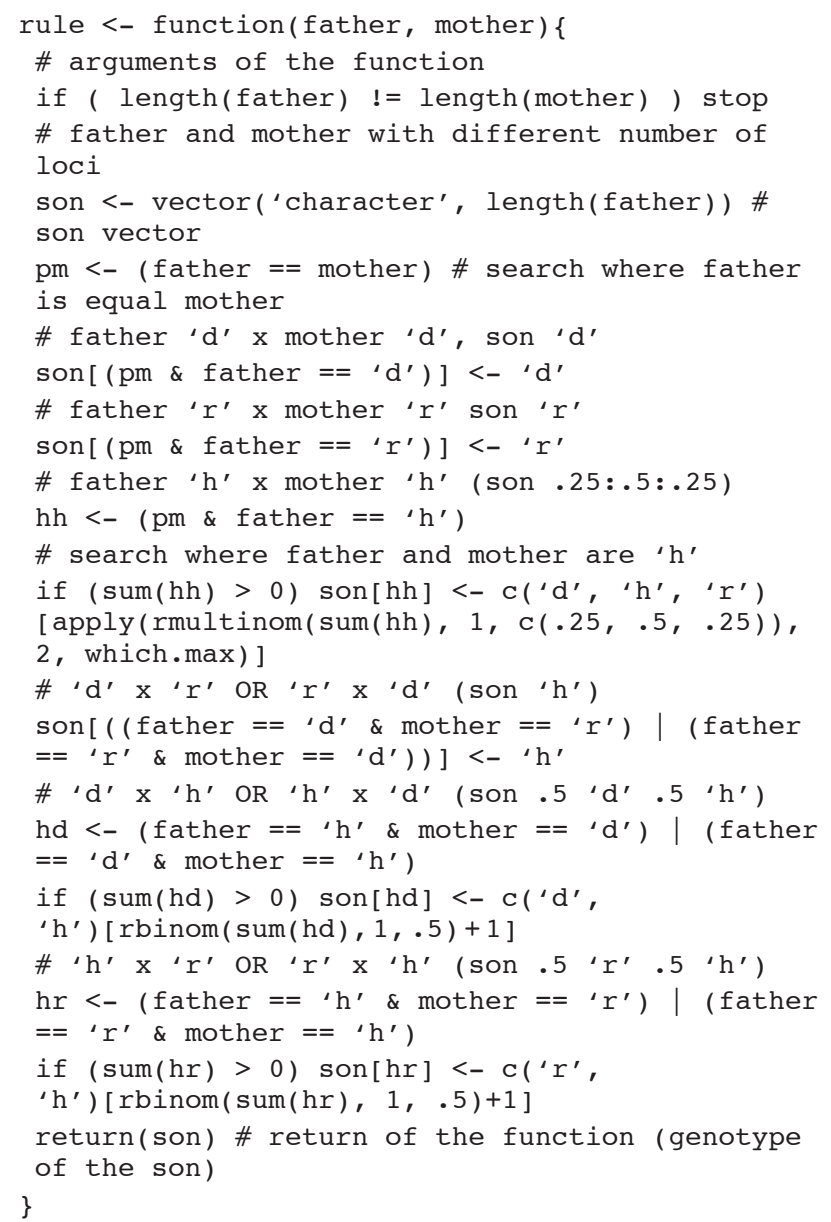

\section{Selection of progenies in cycle zero and recombination strategies}

After the formation of the progenies of full sibs, three selection strategies of individuals were adopted for the next cycle of recurrent selection: a) phenotypic selection: selection of the 20 best individuals regardless of their genealogy; b) selection among and within: selection of the best individuals within the best progenies. In this case, the superior individual was selected within the 20 best progenies; c) selection considering only the mean of the best progenies. In this strategy, the 20 best proge- 
nies were selected and the 20 individuals of each progeny were recombined. Full diallel was performed among the progenies, such that each individual participated in only one cross.

At the time of recombination, the individuals selected in the phenotypic selection and in the selection among and within were recombined two by two, generating at the end 190 progenies of full sibs with 20 individuals with each progeny, making for a total of 3800 individuals.

In recombination of the best progenies, full diallel was carried out among the 20 best progenies, also generating 190 progenies of full sibs. For that purpose, 20 individuals were used from each progeny and each one of them participated only once in each cross.

\section{Estimates of gain with selection in the different methods}

These three recombination strategies were carried out independently for 20 selection cycles of a common population base. The strategy that generated the best clones was verified at the end. This was evaluated by estimating the following parameters in each cycle: phenotypic mean, phenotypic variance, genetic variance and number of fixed alleles. For better visualization, charts were generated with the mean values of the 100 simulations.

At the end of the 20 cycles, the gain achieved with the selection of the different recombination strategies was estimated using the mean values of all the progenies of each cycle. To do so, the difference between the pheno- typic value of the last cycle and of the initial cycle was estimated. This value was divided by the number of cycles to obtain the phenotypic gain achieved per cycle.

\section{Results and Discussion}

In computer simulation, the first premise is the need of consistency in the proposition. According to FERREIRA (2001), the programmer must use validation processes so that the simulated system may operate within similar conditions of the real system and verify if the results generated by simulation are in accordance. To demonstrate this fact, the mean values of heritability in the strategy of selection and recombination of the best individuals, regardless of the genealogy (phenotypic selection), are shown (Table 2). It may be observed that the estimates of heritabilities obtained were practically identical to the values established $a$ priori in the simulation. It was observed that in the configurations in which the heritability is high, and especially when the initial allelic frequency is high, fixation of the alleles occurs rapidly and, consequently, there is no way to estimate heritability.

Another observation regarding to use of simulation is the number of times the process is repeated. The literature reports a range from 10 (WANG et al., 2004) to 500 repeats (WANG et al., 2003) in simulation studies on plant breeding. In this study, 100 times was chosen due to the time and computational resources spent in each configuration. As previously mentioned, with 100 simu-

Table 2. - Estimates of heritabilities in the recombination strategy of the best individuals regardless of genealogy, without dominance.

\begin{tabular}{|c|c|c|c|c|c|c|}
\hline \multirow[b]{4}{*}{ Cycles } & \multicolumn{6}{|c|}{ Heritability } \\
\hline & \multicolumn{2}{|c|}{0.1} & \multicolumn{2}{|c|}{0.5} & \multicolumn{2}{|c|}{1.0} \\
\hline & \multicolumn{6}{|c|}{ Allelic frequency } \\
\hline & 0.2 & 0.8 & 0.2 & 0.8 & 0.2 & 0.8 \\
\hline 0 & 0.1000 & 0.1002 & 0.5007 & 0.4959 & 1 & 1 \\
\hline 1 & 0.1000 & 0.0999 & 0.4998 & 0.4985 & 1 & 1 \\
\hline 2 & 0.1000 & 0.1003 & 0.5021 & 0.5014 & 1 & 1 \\
\hline 3 & 0.1004 & 0.0997 & 0.4979 & 0.4985 & 1 & 1 \\
\hline 4 & 0.1003 & 0.0998 & 0.5008 & 0.5004 & 1 & 1 \\
\hline 5 & 0.1000 & 0.1002 & 0.4998 & 0.5026 & 1 & - \\
\hline 6 & 0.0999 & 0.1002 & 0.5007 & 0.4993 & 1 & - \\
\hline 7 & 0.1001 & 0.1000 & 0.5003 & - & 1 & - \\
\hline 8 & 0.1001 & 0.0998 & 0.5021 & - & 1 & - \\
\hline 9 & 0.1000 & 0.1000 & 0.5002 & - & 1 & - \\
\hline 10 & 0.0998 & 0.1000 & 0.5008 & - & 1 & - \\
\hline 11 & 0.1000 & 0.1002 & 0.5002 & - & 1 & - \\
\hline 12 & 0.1000 & 0.1002 & 0.5005 & - & 1 & - \\
\hline 13 & 0.0999 & 0.0999 & 0.4998 & - & - & - \\
\hline 14 & 0.0999 & - & 0.5006 & - & - & - \\
\hline 15 & 0.1001 & - & 0.5022 & - & - & - \\
\hline 16 & 0.1004 & - & - & - & - & - \\
\hline 17 & 0.0998 & - & - & - & - & - \\
\hline 18 & 0.1001 & - & - & - & - & - \\
\hline 19 & 0.1001 & - & - & - & - & - \\
\hline 20 & 0.0999 & - & - & - & - & - \\
\hline
\end{tabular}


lations, the mean value of heritability expected and predicted was practically equal, showing that the number of replications of simulation per configuration was sufficient.

Heritability estimates available in the literature for volume of wood are varied; nevertheless, the values at the individual level are normally less than 0.4 or $40 \%$ (FLOYD et al., 2003). For other traits, as for example, wood quality, the heritability estimates are also variable, however, with magnitude normally greater than that of volume (APIOLAZA et al., 2005; TOLFO et al., 2005). For that reason, in order to have a greater range of situations, the choice was made to consider heritability ranging from 0.1 to 1.0 .
Another question is the number of selection cycles evaluated. Considering that an IRS cycle in eucalyptus takes eight years, the use of 20 selective cycles would result in 160 years, which evidently is a more than sufficient period to evaluate any breeding strategy.

Recurrent selection is a cyclical breeding process with the goal of growth in the mean value without expressive reduction in genetic variability, so as to continue obtaining gains with selection (HALLAUER, 1999). The effect of selection cycles on the estimate of genetic variance may be observed in Figures 1 and 2. It is worth highlighting that in most situations there was no expressive difference between the methods of phenotypic selection and selection among and within progenies. For that reason,
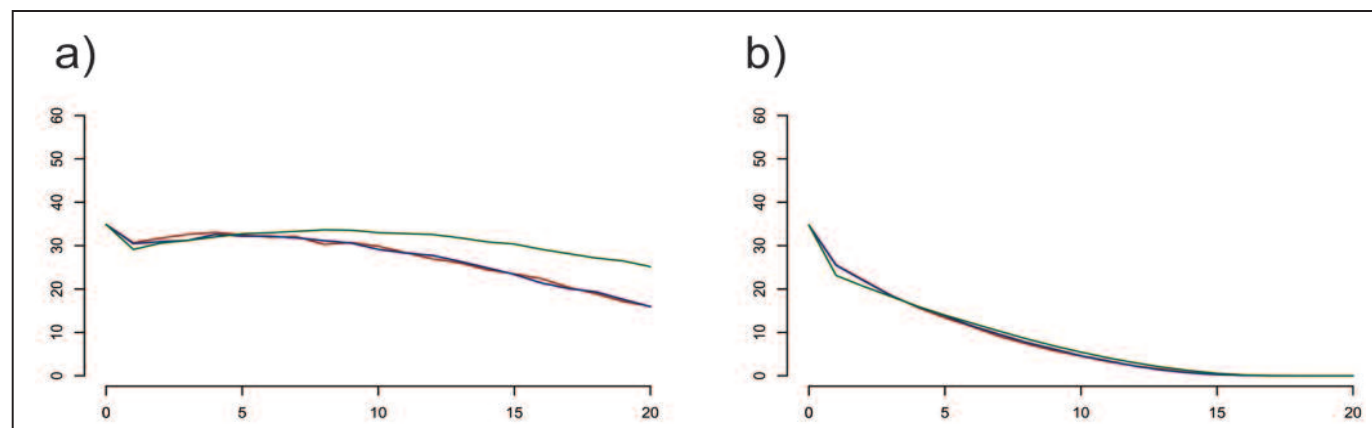

c)

d)
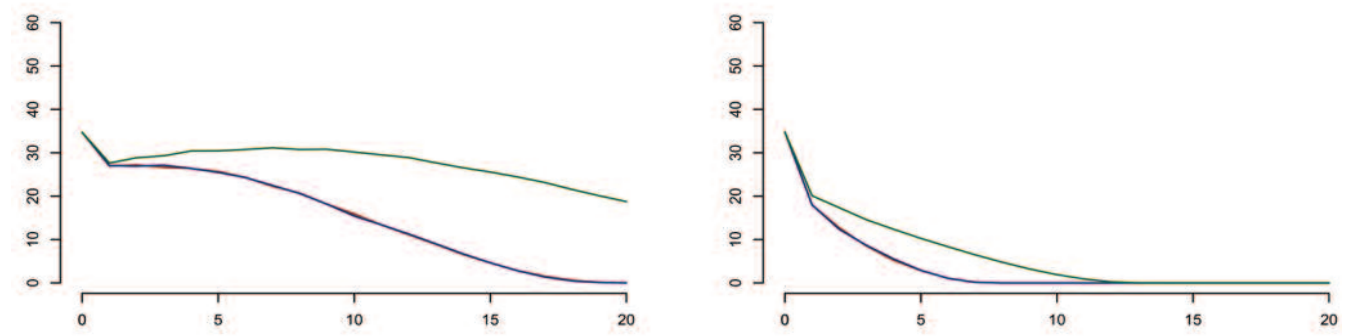

e)

f)
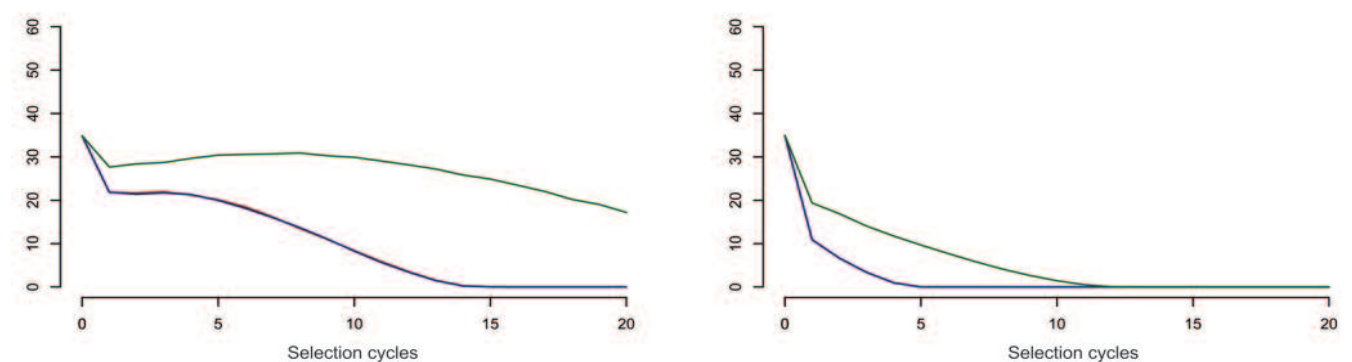

Phenotypic Selection

Selection among and within

Selection of the best progenies

Figure 1. - Genetic variance in the different recurrent selection cycles with average degree of dominance equal to zero and: (a) allelic frequency: 0.2 and heritability: 0.1 ; (b) allelic frequency: 0.8 and heritability: 0.1 ; (c) allelic frequency: 0.2 and heritability: 0.5 ; (d) allelic frequency: 0.8 and heritability: 0.5; (e) allelic frequency: 0.2 and heritability: 1.0; (f) allelic frequency: 0.8 and heritability: 1.0. 


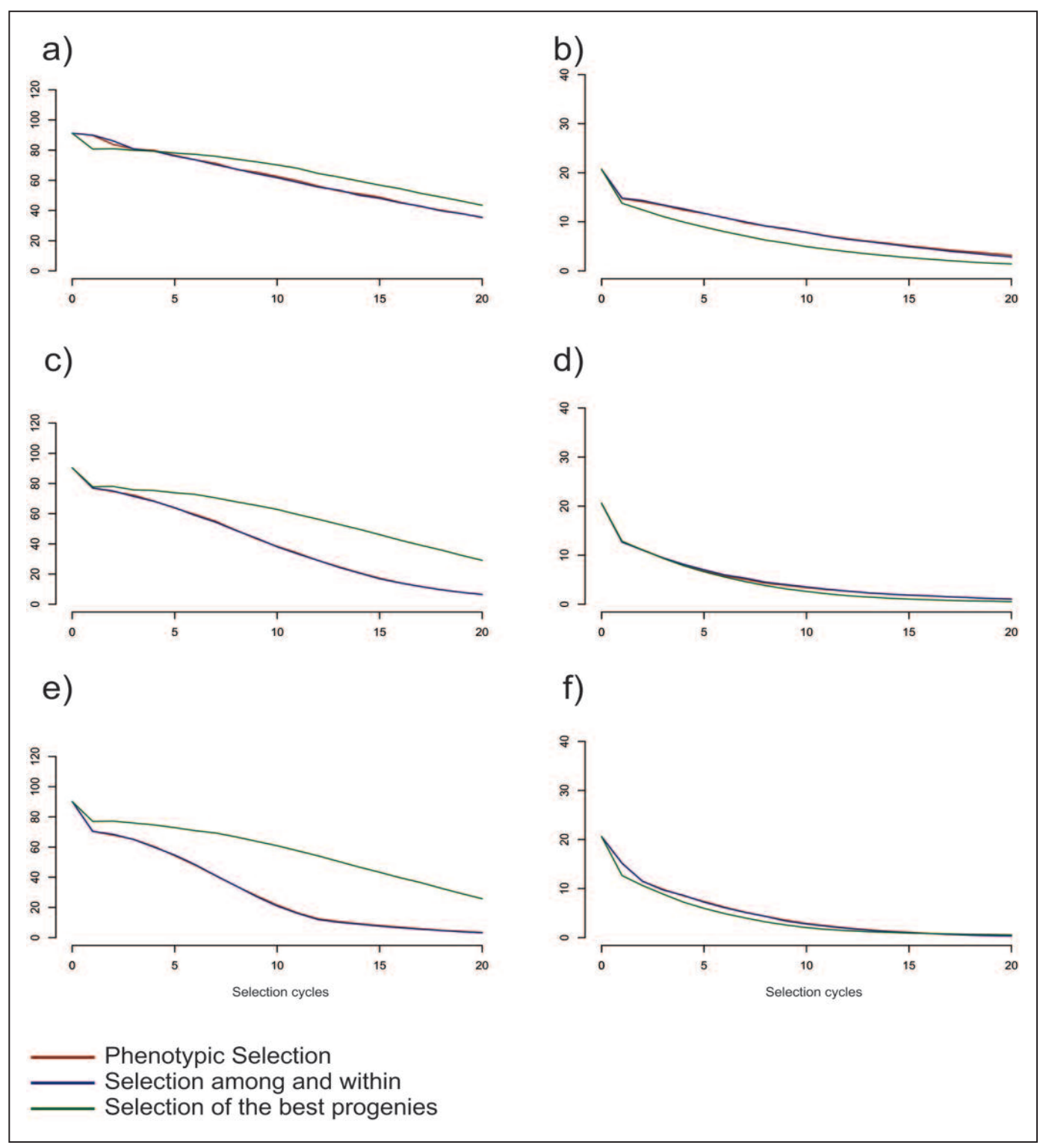

Figure 2. - Genetic variance in the different recurrent selection cycles with average degree of dominance equal to one and: (a) allelic frequency: 0.2 and heritability: 0.1 ; (b) allelic frequency: 0.8 and heritability: 0.1 ; (c) allelic frequency: 0.2 and heritability: 0.5 ; (d) allelic frequency: 0.8 and heritability: 0.5; (e) allelic frequency: 0.2 and heritability: 1.0; (f) allelic frequency: 0.8 and heritability: 1.0 .

the lines of these two selection and recombination methods overlap in the charts. First, it may be seen that the behavior of genetic variance in the different selective cycles varied very little in terms of the type of recombination performed. In all of them, there was reduction in genetic variance, as was expected if selection is efficient. Observe, however, that the reduction of variance is related to heritability and the initial allelic frequency. With low heritability and low allelic frequency, even after 20 selective cycles, with a not very large effective size, genetic variance changed very little with selection. There was a tendency for it to be greater with recombination of progenies. With the increase of heritability, above all for high initial allelic frequency, since the fixation of alleles must be quicker, genetic variance is more rapidly reduced. Proof of this last observation may be obtained by means of the number of fixed loci with favorable alleles during selective cycles.

In the case of average degree of dominance equal to one, in other words, full dominance, it may be observed that genetic variance is more slowly exhausted (Figure 2 ). To explain this, it is enough to use one gene with two alleles as an example. With full dominance, the homozygote with the two dominant alleles and the heterozygote have the same genetic value (1), while the homozygote with recessive alleles has a value of -1 . Genetic variance in this case is 1.33. But in the absence of dominance, the genetic value of the dominant homozygote is one (1), the heterozygote is zero (0) and the recessive homozygote minus one (-1) and the genetic variance comes to be (1). From this example, it is clear that in order to maintain 


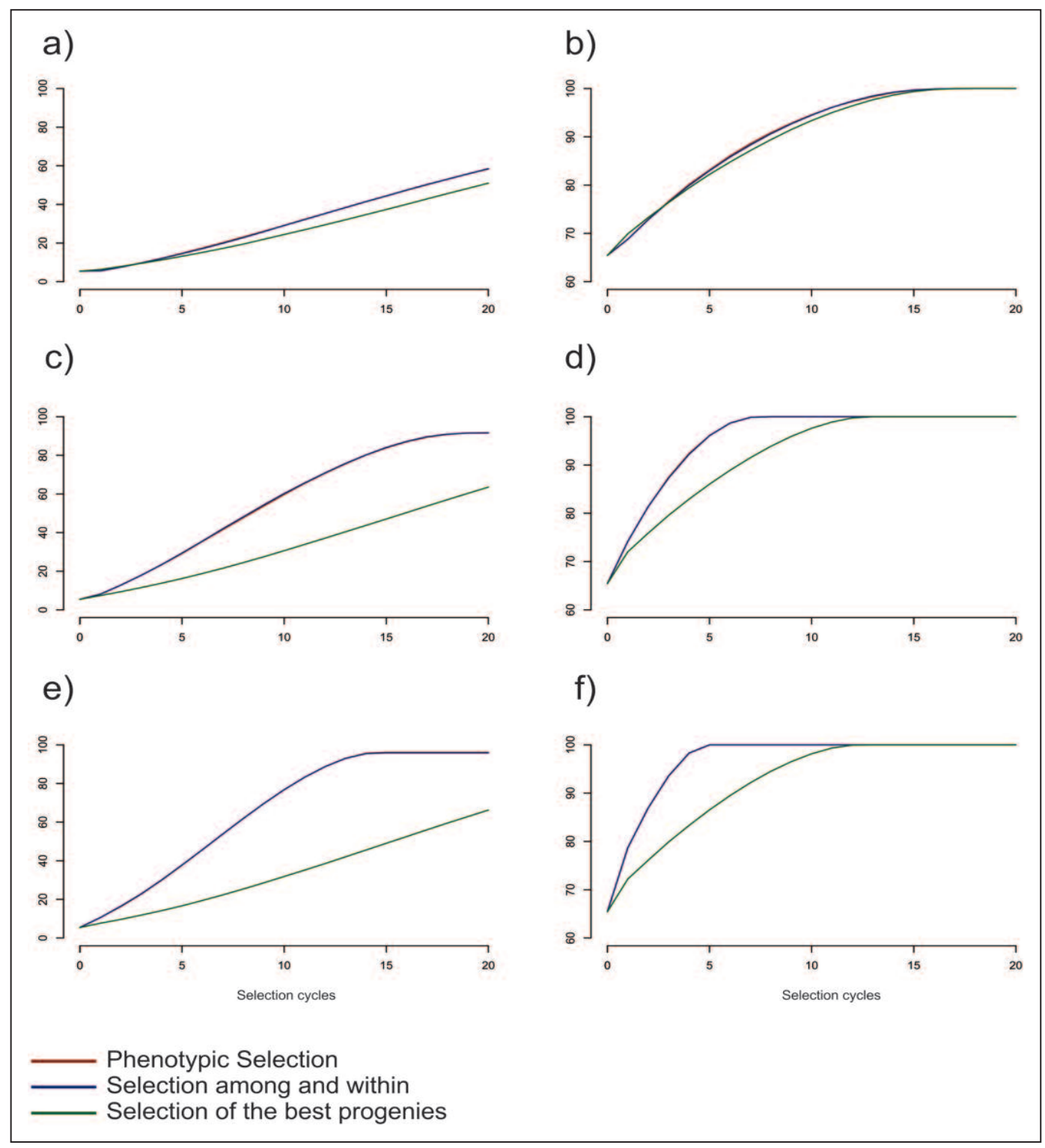

Figure 3. - Number of fixed loci in the different recurrent selection cycles with average degree of dominance equal to zero and: (a) allelic frequency: 0.2 and heritability: 0.1 ; (b) allelic frequency: 0.8 and heritability: 0.1 ; (c) allelic frequency: 0.2 and heritability: 0.5 ; (d) allelic frequency: 0.8 and heritability: 0.5; (e) allelic frequency: 0.2 and heritability: 1.0; (f) allelic frequency: 0.8 and heritability: 1.0.

genetic variance throughout the selective cycles, the average degree of dominance must be considered.

The interaction of dominance hampers selection of superior individuals since the descendents of this individual may have behavior inferior to it (RAMALHO et al., 2012). This fact may be observed in Table 3 because comparing the configurations, changing only the average degree of dominance, the gain achieved is always greater when the absence of dominance is considered.

When one trait is controlled by various genes, in other words, a quantitative trait, the probability of joining all the favorable alleles in one genotype in only one interbreeding cycle is very small (RAMALHO et al., 2012). To get around this problem, recurrent selection proves to be an efficient breeding method because the alleles come to gradually accumulate with advancement in the selection cycles. In the literature there are various recurrent selection methods for the growing of eucalyptus that are promising (RESENDE, 2002; SOUZA JÚNIOR, 2001). KERR et al. (2004), comparing different recurrent selection methods by means of computer simulation, arrived at the conclusion that the use of intrapopulation recurrent selection based on a synthetic population was the most efficient method for increasing the frequencies of favorable alleles.

Among the innumerable advantages of using IRS, the possibility of introducing new genotypes in any selective cycle stands out, with this being a good strategy for 


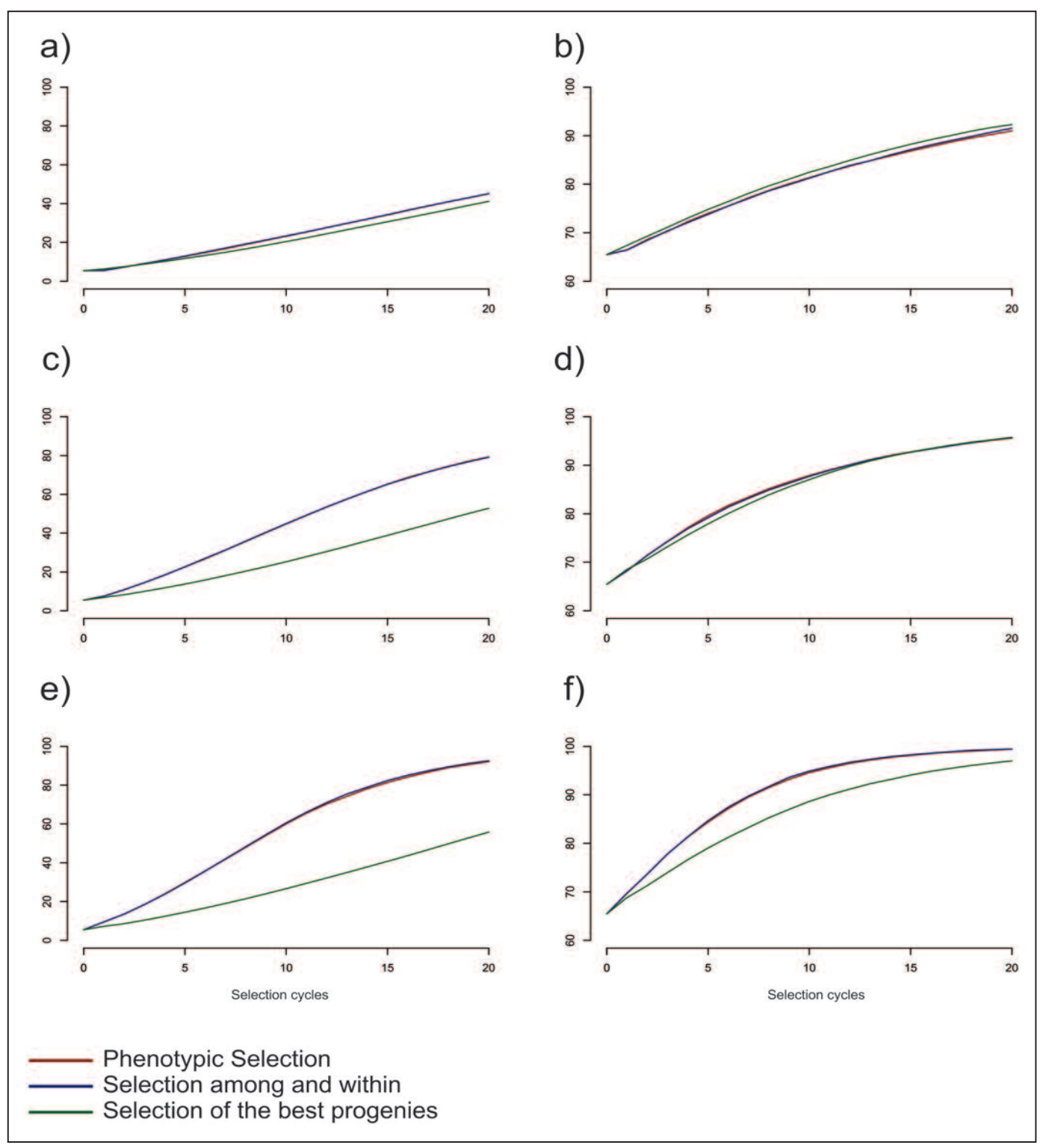

Figure 4. - Number of fixed loci in the different recurrent selection cycles with average degree of dominance equal to one and: (a) allelic frequency: 0.2 and heritability: 0.1 ; (b) allelic frequency: 0.8 and heritability: 0.1 ; (c) allelic frequency: 0.2 and heritability: 0.5 ; (d) allelic frequency: 0.8 and heritability: 0.5; (e) allelic frequency: 0.2 and heritability: 1.0; (f) allelic frequency: 0.8 and heritability: 1.0.

maintaining genetic variation. It is not possible to do this when using RRS, once more showing that intrapopulation recurrent selection should be preferred in genetic breeding of eucalyptus.

There are some reports in the literature saying that when recurrent selection is made in perennial species, as is the case of eucalyptus, remnant seeds (recombination of the best progenies) may be used for recombination (SOUZA JÚNIOR, 2001). In the case in which the average degree of dominance was considered to be zero, and allelic frequency equal to 0.2 and heritability equal to 0.5 and 1 (Figure $3 c, 3 e$ ), the method of recombination of the best progenies was the least efficient, because 20 selection cycles were not enough to fix all the 100 loci, different from the other methods of recombination. With degree of dominance equal to one, no strategy was sufficient to fix all the favorable loci in 20 selection cycles (Figure 4).

To achieve success in a breeding program, there must be sufficient genetic variance to select the best individuals (BERNARDO, 2010). Nevertheless, this variance must be associated with high averages for the genetic gain to be associated with populations or clones that are really advantageous to those who use them. When the best progenies are recombined, it is observed that genetic variation in most cases is of greater magnitude when compared with the other two recombination methods proposed in this study. However, the phenotypic mean, 
likewise in most cases, was less, once more showing that the recombination method of the best individuals of the progenies is better (Figures $5 a, 5 c, 5 d, 5 e, 5 f, 6 c$ and $6 d$ ).

In Figures 5 and 6 are presented the phenotypic means throughout the selection cycles. In all the configurations proposed, there were expressive gains in the three recombination methods; however, it is clear that the strategy of recombination of the best progenies was that which obtained the lowest mean values throughout the selective cycle, in most cases. Considering average degree of dominance equal to zero and low initial allelic frequency (0.2) (Figures $5 a, 5 c, 5 e$ ), the phenotypic means of the recombination strategies of individuals, without consideration of the genealogy (phenotypic selection) and recombination of the best individuals within the best progenies (selection among and within progenies) were similar, while recombination of the progenies with greater mean values was less in all the cycles, regardless of heritability. However, with initial allelic frequency high (0.8), in all cases, recurrent selection was efficient in reaching the maximum phenotypic mean value (all the favorable alleles fixed). However, when the best progenies were recombined, a greater number of cycles in recurrent selection was necessary to reach this level (Figures $5 b, 5 d, 5 f$ ).

To evaluate genetic progress in recurrent selection, various estimators may be used. One of them is the gain achieved per cycle. It may be observed in Table 3 that in all the recombination methods proposed, there was expressive gain throughout the cycles. It is worth highlighting that the gain achieved with selection is more expressive when the initial allelic frequency is low and

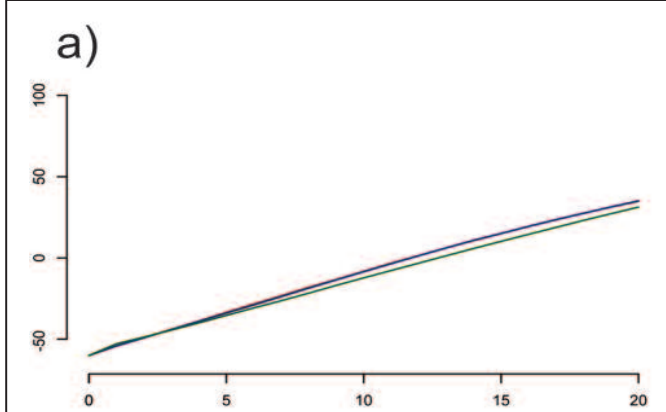

c)

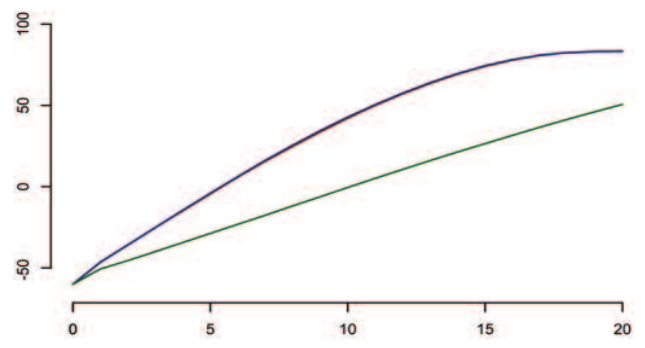

e)

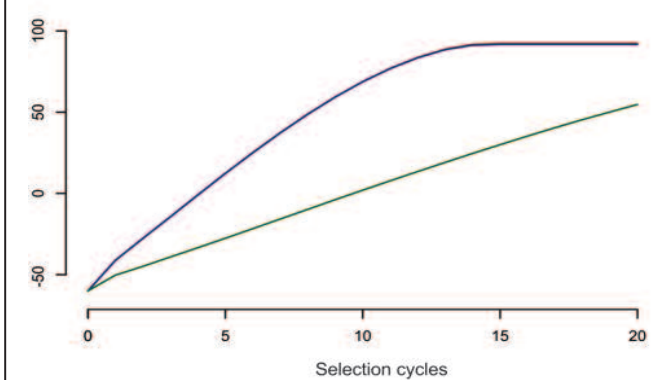

Phenotypic Selection

Selection among and within

Selection of the best progenies b)

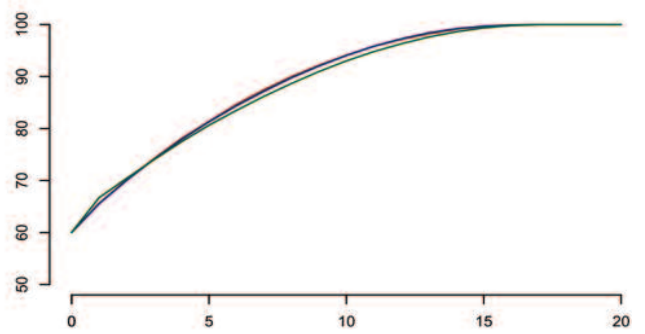

d)

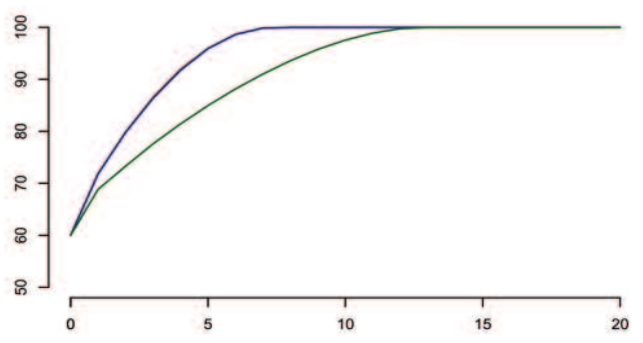

f)

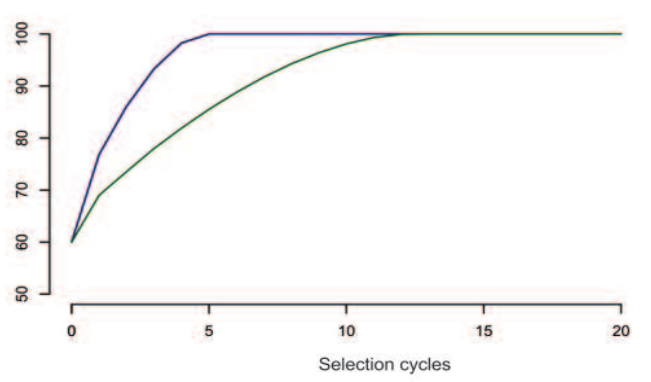

Figure 5. - Phenotypic mean in the different recurrent selection cycles with average degree of dominance equal to zero and: (a) allelic frequency: 0.2 and heritability: 0.1 ; (b) allelic frequency: 0.8 and heritability: 0.1 ; (c) allelic frequency: 0.2 and heritability: 0.5 ; (d) allelic frequency: 0.8 and heritability: 0.5; (e) allelic frequency: 0.2 and heritability: 1.0; (f) allelic frequency: 0.8 and heritability: 1.0. 


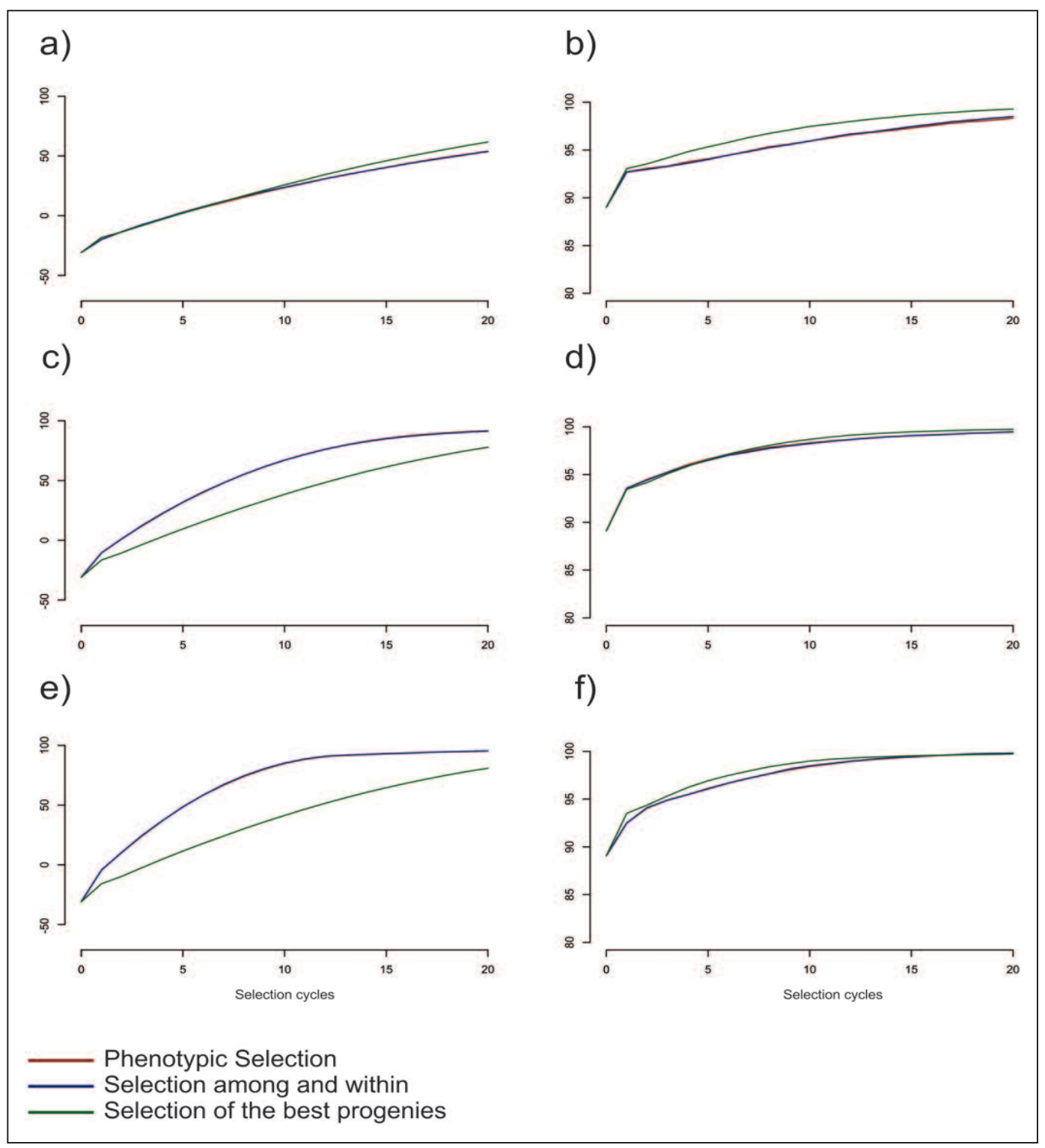

Figure 6. - Phenotypic mean in the different recurrent selection cycles with average degree of dominance equal to one and: (a) allelic frequency: 0.2 and heritability: 0.1 ; (b) allelic frequency: 0.8 and heritability: $0.1 ;$ (c) allelic frequency: 0.2 and heritability: 0.5 ; (d) allelic frequency: 0.8 and heritability: 0.5; (e) allelic frequency: 0.2 and heritability: 1.0; (f) allelic frequency: 0.8 and heritability: 1.0.

when there is an increase of the heritability of the trait. This occurs apart from the average degree of dominance and is evident in the recombination of individuals (phenotypic selection and selection among and within). As in some cases the maximum phenotypic values were reached before completing 20 selective cycles, all the configurations proposed in the gain from the selection were not considered because these values would be underestimated.

The methods of recombination of the best individuals, with or without consideration of their genealogy, were greater than the third method proposed (Table 3). Thus, it is clear that the recombination of the best progenies, in spite of showing gains with selection, was the most inefficient recombination method in recurrent selection.
However, information of the progenies may or may not be used to select the best individuals and afterwards recombine them.

In the present study, as mentioned, the differences between phenotypic selection, in other words, recombination of the best individuals regardless of genealogy, and selection among and within progenies with their respective recombination, were not expressive. This probably occurred because there are progenies with many individuals of superior genetic constitution within it which are selected when phenotypic selection is used, and these individuals within few progenies are as good as the best individuals of the best progenies, since in this second method, only one individual per progeny is selected. As these two methods did not present differ- 
Table 3. - Phenotypic gain achieved in the different methods of recombination.

\begin{tabular}{cccccc}
\hline \multirow{2}{*}{ ADD $^{(1)}$} & \multirow{2}{*}{$\mathrm{h}^{2(2)}$} & \multirow{2}{*}{ Allelic Freq $^{(3)}$} & \multicolumn{3}{c}{ Method of Recombination } \\
\cline { 4 - 6 } & & & Phenotypic Sel. & Among Within Sel. & Best Progenies Sel. \\
\hline 0 & 0,1 & 0,2 & 4,52 & 4,53 & 4,35 \\
0 & 0,5 & 0,2 & 6,83 & 6,82 & 5,27 \\
1 & 0,1 & 0,2 & 4,04 & 4,03 & 4,41 \\
1 & 0,5 & 0,2 & 5,84 & 5,82 & 5,18 \\
1 & 0,5 & 0,8 & 0,49 & 0,49 & 0,51 \\
\hline
\end{tabular}

${ }^{1}$ Average degree of dominance; ${ }^{2}$ Mean heritability; ${ }^{3}$ Initial allelic frequency.

ences, combined selection would probably be the most appropriate selection method because, in this case, an index is generated that results in a differentiated number of progenies and individuals selected per progeny, while in selection among and within, this number is constant.

The methods that recombine the best individuals, considering or not the genealogy, showed the most promising strategies in most cases. However, the average degree of dominance and the heritability of the trait must be considered at the time of choosing the method of selection followed by recombination. The additional advantage of recombination of the best individuals is that they may be cloned. In this case, a milder selection intensity may be applied. The clones obtained in this way would be evaluated and, based on the results, only those with greater performance would be recombined.

\section{Conclusion}

Recombination of the best individuals, regardless of their genealogy, and of the best individuals within the best progenies provided for greater gains than recombination of the best progenies, in most cases.

The average degree of dominance and the heritability of the trait should be considered at the time of choosing the method of selection followed by recombination.

\section{Acknowledgments}

To the CNPq for granting the Research Scholarship to the author GuIlHERme BARBosa ABREU and to Embrapa Informática Agropecuária for lending the computer laboratory.

\section{References}

ApiolazA, L. A., C. A. RaYmond and B. J. Yeo (2005): Genetic variation of physical and chemical wood properties of Eucalyptus globulus. Silvae genetica 54: 160-166.

Assis, T. F., J. F. S. Bauer and G. TAFarel (1993): Sinterização de híbridos de Eucalyptus por cruzamentos controlados. Ciência Florestal 3: 161-170.

Assis, T. F., P. Warburton and C. Harwood (2005): Artificially induced protogyny: an advance in the controlled pollination of Eucalyptus. Australian Forestry 68: 26-32.
BERNARDO, R. (2010): Quantitative traits in plant breeding. Stemma Press, Woodbury, MN.

Bouvet, J. M., A. SAYA and P. Vigneron (2009): Trends in additive, dominance and environmental effects with age for growth traits in Eucalyptus hybrid populations. Euphytica 165: 35-54.

FERREIRA, D. F. (2001): Uso da simulação no melhoramento, pp. 1119-1141. In: Recursos genéticos e melhoramento de plantas, edited by L. L. NASS, A. C. C. VALOIS, I. S. Melo and M. C. VAladAREs-Inglis, Fundação-MT, Rondonópolis/GO.

Floyd, R., R. ARNOLD, G. FARRELl and R. FARRow (2003): Genetic variation in growth of Eucalyptus grandis grown under irrigation in south-eastern Australia. Australian Forestry 66: 184-192.

Gonçalves, F. M. A., G. D. S. P. Rezende, F. L. G. Bertolucci and M. A. P. Ramalho (2001): Progresso genético por meio da seleção de clones de eucalipto em plantios comerciais. Revista Árvore 25: 295-301.

Hallauer, A. R. (1999): Temperate maize and heterosis, pp. 353-361. In: The Genetics and Exploitation of Heterosis in Crops, edited by J. G. Coors and S. PANDEY, ASA, CSSA, and SSSA, Madison, WI.

KerR, R. J., M. J. Dieters and B. Tier (2004): Simulation of the comparative gains from four different hybrid tree breeding strategies. Canadian Journal of Forest Research 34: 209-220.

Pereira, A. B., O. G. Marques Júnior, M. A. P. Ramalho and P. Althoft (1997): Eficiência da seleção precoce em famílias de meios-irmãos de Eucalyptus camaldulensis Dehnh., avaliadas na região noroeste do estado de Minas Gerais. Cerne 3: 67-8.

R Development Core Team. R (2010): A language and environment for statistical computing. Vienna: R Foundation for Statistical Computing. Software.

Ramalho, M. A. P., A. De F. B. Abreu, J. B. dos Santos and J. A. R. Nunes (2012): Aplicações da Genética Quantitativa no Melhoramento de Plantas Autógamas. UFLA, Lavras, MG.

Ramalho, M. A. P., J. B. Dos Santos and C. A. B. P. PINTo (2012): Genética na agropecuária. UFLA, Lavras, MG.

Ramalho, M. A. P., J. B. dos SAntos and M. J. O. ZimmerMANN (1993): Genética quantitativa aplicada ao melhoramento de plantas autógamas: aplicação ao melhoramento de feijoeiro. UFG, Goiânia, GO.

RESENDE, M. D. V. (2002): Genética biométrica e estatística no melhoramento de plantas perenes. EMBRAPA Informação Tecnológica, Brasília, DF. 
Resende, M. D. V., I. E. Pires and R. L. Silva (2011): Melhoramento do Eucalipto, pp. 413-440. In: Pré-Melhoramento de Plantas: Estado da Arte e Experiências de Sucesso, edited by M. A. Lopes, A. P. FAvero, M. A. J. F. Ferreira and F. G. FAleiro. Embrapa, Brasilia, DF.

Shelbourne, C. J. A., S. Kumar, R. D. Burdon, L. D. GeA and H. S. Dungey (2007): Deterministic simulation of gains for seedling and cloned main and elite breeding populations of Pinus radiata and implications for strategy. Silvae Genetica 56: 259-270.

SoUZA JÚNIOR, C. L. (2001). Melhoramento de espécies alógamas, pp. 159-199. In: Recursos genéticos e melhoramento de plantas, edited by L. L. NASS, A. C. C. VALOIS, I. S. Melo and M. C. VAladares-Inglis, Fundação-MT, Rondonópolis.
Tolfo, A. L. T., R. C. Paula, C. A. V. Bonine, A. Bassa and C. F. VALLE (2005) Parâmetros genéticos para caracteres de crescimento de produção e tecnológicos da madeira em clones de Eucalyptus spp. Scientia Forestalis 67: 101-110.

VILLARI, A. C. (2010) Guia do eucalipto: www.cib.org.br. Wang, J., M. van Ginkel, D. Podlich, G. Ye, R. Trethowan, W. Pfeiffer, I. H. Delacy, M. Cooper and S. RAJARAM (2003). Comparison of two breeding strategies by computer simulation. Crop Sci. 43: 1764-1773.

Wang, J., M. van Ginkel, R. Trethowan, G. Ye, I. DeLacy, D. Podlich and M. Cooper (2004). Simulating the eff ects of dominance and epistasis on selection response in the CIMMYT Wheat Breeding Program using QuCim. Crop Sci. 44: 2006-2018. 